\title{
OP-18 IMPROVING ACCESS TO HEALTH IN URBAN SLUMS THROUGH ROLLOUT OF NUHM AND EXPANSION OF COMMUNITY PROCESSES: THE EXPERIENCE OF CHHATTISGARH
}

Samir Garg, Anju Khewar, K Rizu. SHRC - State Health Resource Centre, Raipur (Chhattisgarh), India

\subsection{6/bmjgh-2016-EPHPabstracts. 18}

Background According to the 2011 Census, Chhattisgarh has an urban population of 5.6 million of which $32 \%$ lives in slums. While rural health indicators improved significantly in first decade of 2000, they were almost stagnant in urban environment despite greater availability of secondary public and private healthcare facilities. The state has a Community Health Worker (CHW, known as Mitanin) programme in place in rural areas since 2002, but not in urban areas. Primary healthcare facilities and outreach services were still largely absent in urban slums. In 2012 then, the government of Chhattisgarh launched a State Urban Health Programme with focus on urban slum populations. Its activities were subsumed under the National Urban Health Mission (NUHM) from 2014 onwards. Urban Mitanin CHWs were selected through community consensus; Health Committees (known as Mahila Arogaya Samitis, MAS) were organised; auxiliary nurse midwives (ANMs) were appointed and urban primary health care centres (PHCs) were set up.

Methods A baseline study was conducted in the 11 mostpopulous cities of Chhattisgarh, corresponding to the initial selection of the state's urban health programme, to scrutinise (a) the socio-economic status of households; (b) the utilisation of key healthcare services; and (c) community behaviours and practices regarding key aspects of Reproductive and Child Health. A total of 330 slum clusters were randomly selected for survey. The survey was able to cover 2,134 households with pregnant women, 2,149 households with under- 6 month children, and 2,072 households with 6-24 month children.

Information on the activities of urban Mitanins was collected each month from their facilitators. Field visits were made to verify reports. In each of the first three quarters of 2015, a team of five trained reviewers visited the slums of 19 cities to verify the figures reported on Mitanin and MAS activities. In the process, the reviewers interacted with a total of 285 Mitanins in their cluster meetings, and attended 130 MAS meetings.

Main Findings The baseline survey showed that in comparison to rural areas, urban slums had (1) higher literacy rates; (2) higher access to toilets; (3) lower child malnutrition (underweight); (4) lower immunisation and breastfeeding; (5) less childhood infections except for diarrhoea; (6) lower utilisation 
of family planning services; and (7) higher access to antenatal check-ups and institutional deliveries, though a majority of them were in the private sector. One-third of urban slum households had had a RSBY card, but still 60\% of them incurred high out-of-pocket expenses.

We documented that $3,775 \mathrm{CHW}$ had been selected in slums of 19 towns and that 3,699 MAS had been constituted, covering 1.9 million population in urban slums and adjoining households. The CHWs received 25 days of training over three years. In addition, 220 ANMs recruited under the programme carried out monthly immunisation sessions in slum areas with the help of the CHWs, and 30 urban PHCs were set up.

Analysis of activities reported by the Mitanins from January to September 2015 showed that (1) Mitanins were able to mobilise $80 \%$ of expected deliveries to institutions, $76 \%$ of them in public facilities; (2) $82 \%$ of newborn received designated home visits from Mitanins and $16 \%$ were referred to health facilities when signs of sickness were identified; (3) $87 \%$ of pregnant women received more than three home visits from Mitanins; (4) 63\% of children under three years of age received home visits on nutrition and prevention of infections; (5) 68,400 cases of diarrhoea were given ORS; (6) 120,000 other patients were treated by Mitanins using drug kits; (7) 155 TB suspects per 100,000 population were screened and referred for sputum examination, resulting in 2,140 confirmed cases; (8) 2,796 leprosy suspects were screened and referred, resulting in 611 confirmed cases; and (9) Mitanins intervened in 4,540 cases to oppose violence against women. The MAS worked on health determinants like drinking water, sanitation and functioning of nutrition programmes.

Discussion \& recommendations Expansion of Mitanin CHW and ANM network in urban slums improved access to health dramatically. Mitanins were able to convince large section of the slum populations to access public health facilities. Mitanins provided community-based care and counselling for maternal and child health and for common illnesses. They were able to make their mark within two years of the start of the programme.

Expansion of CHW and related community processes to urban slums was facilitated by the decade-long experience the state had with its Mitanin programme in rural areas. Support structure and training processes for CHWs were kept similar to the rural programme. Timely training, provision of drug kits, emphasis on home visits, focus on social determinants of health, higher literacy amongst CHWs, compact habitations and women getting opportunity to lead activities in social sphere were other facilitating factors. Provision of ANMs conducting regular immunisation sessions in urban slums bridged a very important gap. Linkage with 30 urban PHCs and the presence of hospitals were also important. Impact on indicators like infant mortality rate and under-5 mortality rate still needs to be studied, for slum and non-slum areas separately.

Other factors that facilitated the rollout of the NUHM in Chhattisgarh were (1) commitment of the state; (2) the forerunner state scheme being modelled on lines of the draft NUHM framework; (3) the focus on slums; and (4) the nature of urban slums in the state. The urban context varies in different states and by size of cities.

The NUHM can be extremely valuable for bridging the gap in access to health for the urban poor. Community processes and outreach through ANMs are crucial in urban slums. There is a need to persist with full roll out of NUHM across states.

No competing interest. 